\title{
Avaliação da concentração do crédito BNDES para as empresas do setor sucroalcooleiro brasileiro entre 2002 e 2018 *
}

\author{
Caio César Barboza** \\ Sérgio Rangel Fernandes Figueira ${ }^{* * *}$
}

\begin{abstract}
Resumo
O objetivo do artigo foi o de averiguar como foi distribuído o crédito do BNDES para as 100 maiores empresas, considerando a safra 2012/2013, em moagem de cana-de-açúcar do setor sucroalcooleiro brasileiro no período de 2002 até 2018, mensurando-se ainda comparativamente a concessão de crédito do BNDES e a quantidade de moagem de cana-de-açúcar, a razão de concentração e o coeficiente de Gini. Construiu-se também, comparativamente, curvas de Lorenz. Em todos os indicadores mensurados constatou-se maior concentração e desigualdade na concessão de crédito para as maiores empresas em relação às menores. Observou-se ainda assimetria com relação ao acesso ao crédito, com os maiores tendo maior acesso em relação aos menores. As dez maiores empresas captaram crédito do BNDES. Dos cinquenta maiores, trinta e duas captaram crédito do BNDES. Do quinquagésimo primeiro ao centésimo grupo, sete grupos captaram crédito.
\end{abstract}

Palavras-chave: Concentração, Crédito do BNDES, 100 maiores empresas, Setor sucroalcooleiro.

\section{Abstract}

An analysis of the concentration of BNDES credit to Brazilian sugar and ethanol companies between 2002 and 2018

The goal of the paper was to investigate how BNDES credit was distributed to the 100 largest companies, considering the 2012/2013 harvest, in sugarcane crushing, in the Brazilian sugar and alcohol sector in the period from 2002 to 2018. In addition, a comparative measurement was carried out considering the granting of BNDES credit and the amount of crushed sugarcane, the concentration ratio and the Gini coefficient. Lorenz curves were also constructed comparatively. In all the indicators measured, there was greater concentration and inequality in the granting of credit to the largest companies in relation to the smaller ones. Asymmetry was also observed in relation to access to credit, with the larger companies having greater access in relation to the smaller ones. All ten largest companies have borrowed from the BNDES. Of the fifty largest, thirty-two received credit from the BNDES. From the fifty-first to the hundredth group, seven companies received credit.

Keywords: Concentration, BNDES credit, Top 100 companies, Sugar and alcohol industry.

JEL D22, G2, L1, H2, Q1.

\section{Introdução}

Na década de 2000, o setor sucroalcooleiro brasileiro passou por uma retomada do crescimento da produção canavieira e, consequentemente, da produção de açúcar e álcool. A produção de cana-de-açúcar passou de aproximadamente 326 milhões de toneladas em 2000 para aproximadamente 746,8 milhões de toneladas em 2018 (Instituto Brasileiro de Geografia e Estatística, 2019).

\footnotetext{
${ }^{*}$ Artigo recebido em 30 de março de 2020 e aprovado em 2 de novembro de 2020

** Graduado em Administração pela Faculdade de Ciências Agrárias e Veterinárias - Campus de Jaboticabal - da Universidade Estadual Paulista "Júlio de Mesquita Filho", Jaboticabal, SP, Brasil. E-mail: caiocesarbarbo@hotmail.com. ORCiD: https://orcid.org/0000-0002-4177-1202.

*** Professor Assistente Doutor do Departamento de Economia, Administração e Educação da Faculdade de Ciências Agrárias e Veterinárias - Campus de Jaboticabal - da Universidade Estadual Paulista "Júlio de Mesquita Filho", Jaboticabal, SP, Brasil. E-mail: sergio.rf.figueira@ unesp.br. ORCiD: https://orcid.org/0000-0002-4648-8529.
} 
A expansão da concessão de crédito do Banco Nacional de Desenvolvimento Econômico e Social (BNDES) exerceu papel importante para a expansão da produção de cana-de-açúcar, açúcar e etanol na década de 2000 (Borges; Costa, 2012; Silva, 2017; Milanez; Nyko, 2014; Belik, 2013; Ferracioli; Bacha; Jacomini, 2016). A concessão de crédito permitiu a ampliação da área plantada com cana-de-açúcar, a renovação dos canaviais, os investimentos para compra de máquinas e equipamentos para a construção de novas usinas e a modernização das usinas já existentes (Borges; Costa, 2012).

O crescimento da produção do setor sucroalcooleiro no período foi obtido através de uma maior participação de grupos econômicos com mais de uma unidade produtiva controlando uma maior porcentagem da produção (Baccarin; Gebara; Factore, 2009). Constatou-se ainda crescimento da participação de usinas maiores na moagem, com mais de 2 milhões de toneladas ao ano (Castro; Dantas; Brandão, 2010; Figueira; Perosa; Belik, 2013).

A maior facilidade para obtenção de empréstimos e financiamentos pelos grandes grupos é apontada como um dos fatores responsáveis pelos problemas enfrentados pelas usinas de menor porte. A maior disponibilidade de linhas de crédito e financiamento estimularam a realização de investimentos para ampliação e implantação de novas unidades produtivas com maior escala (Figueira; Perosa; Belik, 2013).

Na literatura econômica, o acesso ao crédito exerce importância na sobrevivência e crescimento da empresa privada, existindo assimetria em seu acesso por parte das grandes empresas, em relação às pequenas e médias. Para Cian, Falkowski e Kancs (2012), a obtenção de crédito é um fator crucial para determinar o desempenho e o desenvolvimento da empresa privada. A restrição de crédito limita o uso de insumos pelas empresas e a capacidade de realização de investimentos. Possas (1990) e Ferguson (2003) salientam uma maior facilidade e menores juros para o financiamento das grandes empresas em relação às pequenas e médias. Ubesie, Onuaguluchi e Mbah (2017) alertam para a importância do crédito bancário para as pequenas e médias empresas realizarem investimentos.

Borges e Costa (2012), analisando o destino do crédito do BNDES entre 2002 e 2008, constataram uma maior destinação do crédito para a região Centro-Sul, principalmente para o estado de São Paulo, intensificando a diferença de produtividade entre a região Centro-Sul e a Norte-Nordeste. Silva (2017) destaca o fato de o Estado brasileiro em geral, e a concessão de créditos do BNDES em particular, em suas diferentes escalas de atuação, tender a agir em conformidade com os interesses dos grandes grupos econômicos, guiado pela lógica empresarial de crescimento da produção e sem considerar os custos sociais e as implicações territoriais desse processo.

Existe carência na literatura em avaliar se as maiores empresas do setor sucroalcooleiro receberam uma maior quantidade de crédito do BNDES em relação às menores na década de 2000, período de crescimento do setor. Para auxiliar nesta discussão, o objetivo geral do trabalho é o de mensurar como foi distribuído o crédito do BNDES para as cem maiores empresas do setor sucroalcooleiro e a ocorrência de desigualdade no repasse destes créditos no período de 2002 até 2018.

Para se cumprir o objetivo geral, o trabalho irá mensurar os seguintes objetivos específicos: 
- Concessão de crédito para as cem maiores empresas em moagem de cana-de-açúcar do setor sucroalcooleiro e os valores absolutos de moagem destes grupos;

- Mensuração da razão de concentração por concessão de crédito do BNDES e por moagem dos grupos sucroalcooleiros;

- Construção da Curva de Lorenz por concessão de crédito do BNDES e por moagem dos cem maiores grupos do setor sucroalcooleiro;

- Mensuração do Coeficiente de Gini por concessão de crédito do BNDES e por moagem do grupo sucroalcooleiro.

Pretende-se com a pesquisa, testar a hipótese de que os maiores grupos econômicos receberam uma maior quantidade de crédito do BNDES no período analisado, potencializando o seu crescimento e a maior competitividade em relação aos menores grupos.

Justifica-se a realização deste trabalho pela contribuição acadêmica e de políticas públicas. Do ponto de vista acadêmico, testar a hipótese de concentração de crédito do BNDES para os grandes grupos do setor sucroalcooleiro em detrimento dos pequenos e médios, contribui para os estudos de política pública e de organização industrial, em especial com os trabalhos de Silva (2017) e Borges e Costa (2012), pelos quais analisaram os destinos dos créditos do BNDES na década de 2000. O trabalho pode auxiliar na compreensão dos fatores desencadeadores da concentração do setor sucroalcooleiro vivenciados na década de 2000 como apontam Baccarin, Gebara e Factore (2009), Castro, Dantas e Brandão (2010) e Figueira, Perosa e Belik (2013).

Além da introdução, elaborou-se uma revisão de literatura com o intuito de construir as bases teóricas para o trabalho e apresentar evidências empíricas. Posteriormente, apresentam-se os materiais e métodos e, na sequência, os resultados e discussões, encerrando-se com as conclusões.

\section{Revisão de literatura}

Inicia-se a revisão de literatura com a fundamentação teórica definindo os principais motivos para a existência da economia de escala, com ênfase na economia de escala pecuniária relativa ao maior acesso ao crédito. Posteriormente, discute-se o impacto da restrição de crédito para as empresas privadas que deixam de realizar investimentos. Posteriormente, apresenta-se a evolução do setor sucroalcooleiro na década de 2000 e os principais fatores responsáveis pela economia de escala e a concentração do setor. Finaliza-se o tópico com a concessão de crédito do BNDES para o setor sucroalcooleiro e os fatores que justificam a hipótese de ocorrência de desigualdade e concentração na concessão de crédito para as empresas do setor sucroalcooleiro.

\section{Fundamentação teórica}

\section{(i) Economia de escala}

As economias de escala são as vantagens de custos de produção das grandes empresas em relação às menores (Pindyck; Rubinfeld, 2004). Possas (1990) classifica as fontes de economias de escala em três: economia técnica de escala, obtida no nível da planta industrial, economia de escala atribuída ao nível do processo de produção e economias de escala atribuída à firma, abrangendo empresas com várias plantas industriais. 
Obtêm-se a economia técnica de escala como decorrência das seguintes causas: (1) ampliação das unidades individuais devido aos seguintes fatores: (1.1.) economias geométricas, dizendo respeito às propriedades geométricas das unidades processadoras, comuns em processos químicos e metalúrgicos. O produto destas unidades tende a ser proporcional ao volume da unidade, enquanto o custo associado à produção é proporcional à área da superfície das unidades processadoras (Lootty; Szapiro, 2002; Possas, 1990); (1.2) indivisibilidade técnica: como nem sempre é possível comprar equipamentos com um tamanho exato para produzir a quantidade de produto exatamente necessária, possíveis subutilizações do equipamento podem servir para uma futura expansão produtiva (Lootty; Szapiro, 2002; Possas, 1990); (2) Custo decrescente da operação ligado à utilização mais eficiente da força de trabalho relacionada à maior especialização e à indivisibilidade da mão-de-obra especializada e de menores despesas de supervisão, administração e manutenção. Lootty e Szapiro (2002) adicionam a lei dos grandes números, pela qual a equipe e os materiais utilizados para reposição e conserto de peças destinadas a manter qualquer nível de atividade produtiva frente à possibilidade de problemas técnicos, cresce menos do que proporcionalmente em relação ao número de máquinas em operação.

A economia de escala atribuída ao processo de produção está ligada a uma produção ininterrupta e com crescente especialização da força de trabalho ao longo do tempo.

Por fim, a economia de escala obtida ao nível da firma se refere às economias multiplantas e às pecuniárias, reduzindo os custos de obtenção de matérias-primas, devido à compra em grande escala. Dentre as economias de escala puramente pecuniárias, as mais importantes são as que resultam do acesso diferenciado de empresas de distintos tamanhos ao mercado de capitais, implicando taxas de juros mais altas ou a recusa de crédito para empresas de menor tamanho. Existindo o menor risco do empréstimo ou investimento financeiro em grandes empresas pela maior estabilidade dos seus lucros, pela maior margem corrente de lucros implicando maior segurança de ressarcimento da dívida ou pela maior capacidade de diversificar as possibilidades de ganho reduzindo o risco de perdas e inadimplência (Possas, 1990).

O desempenho das pequenas e médias empresas (PMEs) está amplamente relacionado à disponibilidade de crédito dos bancos, permitindo-se ampliar os investimentos (Lawal et al., 2019). O crédito bancário desempenha um papel importante no desenvolvimento da economia, e as pequenas e médias empresas necessitam do crédito para a realização de investimentos (Ubesie; Onuaguluchi; Mbah, 2017).

Possas salienta evidências empíricas das vantagens relacionadas ao acesso do crédito. Em um mercado onde os juros respondem a diferentes níveis de risco e onde existe aversão ao risco da parte dos investidores, as taxas de juros diferenciadas pelo tamanho das empresas tomadoras serão inexoráveis (Possas, 1990). Ferguson (2003) salienta também o fato do financiamento de empresas de grande escala ser normalmente mais fácil e menos dispendioso em relação às demais.

\section{A restrição de crédito e seus impactos para uma empresa privada}

A restrição de crédito é identificada como um fator crucial para determinar o desempenho e o desenvolvimento da empresa privada. Constata-se que a restrição de liquidez limita o uso de insumos pelas empresas, não apenas nos países em desenvolvimento, mas também nas economias desenvolvidas. Na presença de uma restrição de crédito vinculativa, um acesso melhorado ao crédito pode levar ao aumento da produtividade e à produção tanto no curto como no longo prazo (Ciani; Falkowski; Kancs, 2012). 
O acesso limitado ao crédito agrícola foi identificado como fator restritivo para o desenvolvimento agrícola de pequenos agricultores em muitos países em desenvolvimento. Consequentemente, o acesso e uso do crédito agrícola têm sido considerados instrumento para aumentar a produção agrícola e melhorar os meios de subsistência rurais (Shiferaw; Gebremedhin; Zewdie, 2017). Assim como na agricultura, a restrição de crédito impacta também em pequenas e médias empresas em outros setores.

Inúmeros fatores limitam o acesso ao crédito, apresentando desigualdade e seletividade na disponibilidade de recursos para os produtores, principalmente para os de pequeno e médio porte com maior necessidade de crédito (Souza; Ney; Ponciano, 2015).

A concessão de crédito é condicionada pelo risco, podendo ser definida como 'o potencial de uma parte contratual deixar de cumprir suas obrigações de acordo com os termos acordados' (Brown; Moles, 2014). Para Brito e Assaf Neto (2008), a concessão de crédito possui risco de não pagamento nas condições pactuadas. Conforme Brito, Assaf Neto e Corrar (2009), a expectativa de risco de default associada ao tomador é representada por uma medida (rating) atribuída pelos sistemas de classificação de risco, podendo ser expressa na forma de uma letra ou número, inserida numa escala com parâmetros previamente estabelecidos.

$\mathrm{O}$ risco de default, também conhecido como risco cliente, está ligado diretamente a condições intrínsecas ao postulante que apontam favoravelmente ou negativamente ao fato de o mesmo ter condições de pagar o(s) compromisso(s). Não sendo este o único risco envolvido no processo, há também o risco da operação em si, que está associado a fatores específicos de cada operação, incluindo os riscos de exposição e de recuperação (Brito; Assaf Neto, 2008).

A atividade de classificação de risco também é realizada no mercado financeiro brasileiro por alguns grandes bancos atacadistas, geralmente multinacionais, com o objetivo de diferenciar, para uso interno, os níveis de risco de grandes empresas. Também são de uso corrente os sistemas de escores, voltados para orientar a concessão de crédito para o mercado de varejo e para pessoas físicas. O BNDES dispõe de um sistema de classificação de risco (SCR) desde o final de 1993, utilizado para avaliar o nível de risco das empresas, de grupos econômicos e de entidades que se relacionam diretamente com a Instituição (Bergamini Junior, 1997).

Um dos grandes fatores geradores de restrições de crédito consiste na informação assimétrica, pela qual não se sabe se a outra parte irá honrar com os seus compromissos. A informação assimétrica decorre da seleção adversa e do risco moral. A seleção adversa acontece devido aos tomadores (agentes) conhecerem melhor sua capacidade de saldar a dívida, ao contrário do emprestador (principal). O risco moral advém do não pagamento da dívida como decorrência de diferentes conjunturas do mercado (Santos; Braga, 2013).

Conforme Stiglitz e Weiss (1981), o retorno esperado para o banco irá depender da probabilidade de pagamento do emprestador, sendo difícil identificar os bons emprestadores dos maus emprestadores. Para reduzir riscos, o banco necessita adotar triagem para a concessão de crédito. O montante de garantias exigido irá afetar tanto o montante de crédito concedido como selecionará os tomadores de empréstimo que conseguirão obter crédito.

Ciaian e Swinnen (2009) fazem uma reflexão sobre a restrição de crédito para os produtores rurais devido a assimetria de informações. Na existência de informações assimétricas, a avaliação para a concessão de crédito irá depender da reputação do produtor, do tamanho da fazenda e da riqueza do proprietário. Portanto, quem está concedendo crédito avalia estes itens 
para selecionar quem obterá crédito e quem não irá obter crédito. Esta reflexão pode ser adaptada para outros segmentos, como a concessão de crédito para grupos econômicos do setor sucroalcooleiro.

As políticas de subsídio podem reduzir as restrições de crédito e consequentemente as imperfeições de mercado, facilitando o desenvolvimento das empresas que apresentam dificuldades na obtenção de recursos para financiar suas atividades (Ciaian; Swinnen, 2009).

\section{Economia de escala e concentração da produção sucroalcooleira brasileira}

Entre 1933 e 1990, o estado brasileiro adotou uma posição intervencionista com relação ao setor sucroalcooleiro, estabelecendo controle da produção por meio do Instituto do Açúcar e do Álcool (IAA). O IAA tinha como objetivo regular e planejar a produção do setor sucroalcooleiro (Baccarin, 2011). Na década de 1960, as políticas públicas para o setor pautaramse no estímulo para o seu crescimento e o ganho de eficiência através das economias de escala. Com o intuito de aprimorar a eficiência do setor implantou-se o Programa de Racionalização da Agroindústria Açucareira - posteriormente denominado Programa de Apoio à Agroindústria Açucareira. Promovia-se o financiamento das fusões e aquisições e do crescimento das unidades produtivas com o intuito de aprimorar a competividade através de ganhos de escala. Além disto, o Instituto do Açúcar e do Álcool, utilizando os recursos do Fundo de Exportação, passou a financiar a expansão das unidades, o seu reequipamento e até mesmo as novas localizações das unidades produtivas (Ferreira; Alves, 2009).

No período entre 1960 e 1990, o número de agroindústrias sucroalcooleiras foi muito influenciado por políticas públicas. Na execução do Plano de Expansão da Indústria Açucareira Nacional, a partir de 1963, e do Programa de Racionalização da Agroindústria Açucareira, de 1971, estimulou-se o crescimento do tamanho médio das usinas, procurando-se eliminar plantas consideradas tecnologicamente atrasadas e ineficientes (Baccarin; Gebara; Factore, 2009).

Foi elaborado no Proálcool (Programa Nacional do Álcool) um conjunto de políticas públicas para incrementar a produção e a utilização do álcool combustível no Brasil, e o número de agroindústrias sucroalcooleiras passou de 225, na safra 1974/75, para 366, em 1984/85 e, posteriormente, para 394, em 1990/91. Já a capacidade média elevou-se de 33,7 mil toneladas de açúcar equivalente em 1974/75 para 58,6 mil toneladas de açúcar equivalente em 1984/85 e, para 59,5 mil toneladas de açúcar equivalente em 1990/91 (Baccarin, 2005).

A partir dos anos 1990, ocorreram reformas liberais na política econômica brasileira. Neste período, ocorre a extinção do Instituto do Açúcar e do álcool (IAA), deixando-se de fixar cotas de produção para as usinas e estados canavieiros e eliminando-se o monopólio público nas exportações do açúcar e a exigência de licenças prévias para exportação de álcool e açúcar, ocorrendo também liberalização dos preços no setor sucroalcooleiro (Baccarin, 2011).

Neste cenário de desregulamentação do setor, inicia-se um novo ciclo de crescimento do setor impulsionado pela crescente demanda internacional por açúcar, pelo rápido crescimento das vendas de veículos flex-fuel no mercado brasileiro, impulsionando o mercado interno de etanol, e pela expectativa favorável de exportação de etanol combustível (Belik et al., 2017).

Pesquisas de Baccarin, Gebara e Factore (2009), Castro, Dantas e Brandão (2010), Figueira, Perosa e Belik (2013), Figueira, Belik e Vicente (2014a) e Figueira, Belik e Vicente (2014b) analisaram a variação da economia de escala e da concentração da moagem de cana-de- 
açúcar no Brasil. Baccarin, Gebara e Factore (2009) salientam o fenômeno do crescimento da produção sucroalcooleira entre a safra 1990/91 e 2001/2002 ser marcada por redução do número de usinas produtoras e elevação da capacidade média. No Brasil, ocorreu redução de 394 unidades em 1990/91 para 306 unidades entre 2001/2002. Na região Norte/Nordeste, ocorreu redução do número de usinas de 126 em 1990/1991 para 83 em 2001/2002. Na região Centro/Sul ocorreu decrescimento do número de usinas de 268 para 223 no período. Quanto à capacidade média, em açúcar equivalente, ocorreu crescimento de 59,5 mil toneladas equivalentes em 1990/91 para $113,2 \mathrm{em} \mathrm{2001/2002.}$

Segundo Castro, Dantas e Brandão (2010), as usinas que moem até 1 milhão e 2 milhões de toneladas/safra tiveram redução na participação na moagem comparando as safras de 1999/2000 e 2008/2009 no estado de São Paulo, passando respectivamente de 14,8\% em 1999/00 para $6,1 \%$ na safra $2008 / 09$ e de $37,2 \%$ para $25,4 \%$. Constatou-se ainda crescimento na participação de usinas com escala de moagem entre 2 e 3 milhões de toneladas, 4 a 5 e mais de 5 milhões de toneladas. $\mathrm{O}$ tamanho das usinas com maior crescimento na participação na produção foi o de 2 a 3 milhões de toneladas, passando de 15,3\% para 29,4\% na produção paulista.

Figueira, Belik e Vicente (2014a) constataram uma maior participação na moagem de usinas com mais de cinco milhões de toneladas. O maior crescimento da participação na moagem entre 1999/00 e 2012 foi de usinas com mais de cinco milhões de toneladas. No ano de 2012, este extrato de moagem passou a deter a maior participação na moagem paulista, 28,6\%. Na outra ponta, vem ocorrendo redução da participação na moagem de usinas com menos de dois milhões de toneladas.

Tabela 1

São Paulo: participação das usinas na moagem de cana-de-açúcar no período 1999/2000, 2008/2009 e 2012

\begin{tabular}{l|c|c|c}
\hline Escala de Moagem & $\begin{array}{c}99 / 00 \\
\%\end{array}$ & $\begin{array}{c}08 / 09 \\
\%\end{array}$ & $\begin{array}{c}2012 \\
\%\end{array}$ \\
\hline$>5$ & $9,7 \%$ & $12,9 \%$ & $28,6 \%$ \\
\hline 4 a 5 & $8,7 \%$ & $12,5 \%$ & $7,9 \%$ \\
\hline 3 a 4 & $14,0 \%$ & $13,6 \%$ & $22,5 \%$ \\
\hline 2 a 3 & $15,3 \%$ & $29,4 \%$ & $24,3 \%$ \\
\hline 1 a 2 & $37,2 \%$ & $25,4 \%$ & $15,6 \%$ \\
\hline Até $1 \mathrm{~m}$ & $14,8 \%$ & $6,1 \%$ & $1,10 \%$ \\
\hline Total & $100,0 \%$ & $100,0 \%$ & $100 \%$ \\
\hline
\end{tabular}

Fonte: As safras 1999/2000 e 2008/2009 foram coletadas em Castro, Dantas e Brandão (2010), o ano de 2012 foi elaborado com informações contidas em Figueira, Belik e Vicente (2014a).

A maior facilidade para obtenção de empréstimos e financiamentos pelos grandes grupos é apontada como um dos fatores responsáveis pelos problemas enfrentados pelas usinas de menor porte. A maior disponibilidade de linhas de crédito e financiamento estimularam a realização de investimentos para ampliação e implantação de novas unidades produtivas com maior escala. Além do acesso ao crédito, o maior poder de negociação da usina com os fornecedores é decorrente do ganho de escala e dos grupos que conseguem negociar insumos para diferentes unidades produtivas como vantagem para as usinas com maior escala e os grandes grupos em relação aos grupos econômicos menores e menos capitalizados (Figueira; Perosa; Belik, 2013). 


\section{Crescimento dos grupos econômicos e concentração de mercado}

Além da maior escala das usinas constatou-se, a partir da década de 1990, crescimento de alguns grupos privados controlando a produção de várias usinas espalhadas inclusive em diferentes estados produtores. A estratégia de crescimento multiplanta das empresas no setor desencadeou maior concentração produtiva em grandes grupos privados, como relatado em Ferreira e Alves (2009) e Baccarin, Gebara e Factore (2009).

Para Ferreira e Alves (2009), a expansão vivenciada pelo setor a partir da década de 1990 ocorreu principalmente pelo surgimento de unidades filiais das que já existiam. Ao invés de ocorrer um processo de pluralização de novas unidades industriais pertencentes a empresas ou grupos divergentes dos que já existiam, ocorreu um processo de fortalecimento de alguns grupos.

Segundo Baccarin, Gebara e Factore (2009), na primeira década do século XXI observouse fortalecimento econômico e produtivo de grupos já existentes ou que estavam se estabelecendo no mercado através da incorporação de outras unidades por meio de fusões e aquisições, da ampliação de unidades já existentes e da implantação de novas unidades. Neste trabalho, foi avaliada a evolução da concentração do setor sucroalcooleiro entre 2000 e 2007, mensurando-se a razão de concentração (CR4) e o Índice Hirchman-Herfindahl (IHH) para a região Centro-Sul. O trabalho constatou crescimento da concentração econômica, pelo qual grupos econômicos detendo mais de uma usina ampliaram a participação na moagem de cana-de-açúcar passando de um CR4 de 16,3 para 17,9, e o IHH passou de 151,9 para 232. Embora tenha ocorrido crescimento, o índice de concentração se manteve relativamente baixo quando se utiliza dos índices de concentração das agências antitrustes como o CADE.

Com o intuito de se atualizar a avaliação da concentração por usina e por grupo econômico na moagem paulista em 2012, o trabalho de Figueira, Belik e Vicente (2014b) mensurou a razão de concentração e o IHH por grupo econômico. Constatou-se IHH de 498,9 por grupo. Comparando-se os índices de concentração da moagem no estado por usina e por grupo, constatou-se maior concentração dos grupos em relação à moagem individual. O CR1 por usina foi de 0,02 e de 0,18 por grupo. O CR5 por usina foi de 0,10 e de 0,34 por grupo. O CR 10 por usina foi de 0,17 e de 0,48 por grupo. O CR 15 por usina foi de 0,23 e de 0,56 por grupo.

Ressalta-se ainda a entrada de grupos econômicos internacionais produtores de açúcar de outros países, como a Tereos, Trading Companies como a Louis Dreyfus Commodities (LDC), Cargill e Bunge, e petrolíferas como a BP e a Shell. A entrada destes grupos foi primordialmente mediante fusões e aquisições ou joint ventures. A participação das empresas estrangeiras na capacidade de moagem passou de 8\% em 2008 para 32\% em 2011 (Pinto, 2011).

\section{Crédito do BNDES para o setor sucroalcooleiro}

O crescimento do setor sucroalcooleiro na década de 2000 foi impulsionado pela expansão do crédito rural e dos bancos oficiais. Entre as instituições financeiras fomentadoras de crédito para a agroindústria, os bancos oficiais disponibilizam os recursos obrigatórios decorrentes de exigibilidades além de uma parcela de recursos livres e também promoveram financiamentos rurais lastreados em recursos externos, repasses do BNDES e instrumentos especiais como a caderneta verde, etc. Tomando-se o ano de 2011, os recursos obrigatórios representavam 28,5\% das fontes para crédito, a poupança rural tinha 19,4\%, os fundos constitucionais também com $19,4 \%$ e os recursos do BNDES com $24,5 \%$ do total. Merece destaque o crescimento da participação do BNDES em investimentos para o setor, alcançando o montante de R \$ 1,6 bilhão em 2011 (Belik, 2013). 
A partir de 2003, passou a ocorrer crescimento do crédito do BNDES para o setor sucroalcooleiro, atingindo o seu maior patamar no ano de 2010. Neste período, a concessão de crédito do BNDES para o setor se ampliou em aproximadamente dez vezes (Milanez; Nyko, 2012), destacando-se a realização de políticas anticíclicas realizadas pelo BNDES com o intuito de amenizar os efeitos da crise de 2008 , com a crise imobiliária norte-americana e a retração do crédito mundial sobre o setor sucroalcooleiro, elevando a oferta de crédito no mercado e, assim, buscando suavizar as flutuações econômicas (Ferracioli; Bacha; Jacomini, 2016).

Silva (2017) salienta a relevância do crescimento dos créditos do BNDES para a expansão da produção do setor sucroalcooleiro na década de 2000, através da expansão da área plantada, renovação do canavial, construção de novas usinas e modernização das já existentes. $\mathrm{O}$ financiamento, no período, foi destinado para as seguintes finalidades: capital de giro ou fundos variados, expansão de unidades produtivas para cogeração de energia, infraestruturas logísticas, pesquisas, plantações e renovações de canaviais e infraestrutura das unidades produtivas em geral.

Na década de 2000, o BNDES pautou sua atuação no setor sucroalcooleiro em cinco diretrizes principais que são: i) a ampliação da capacidade de produção - ocorrendo crescimento no período de aporte do banco para ampliação da produção do setor. Criou-se em 2007 uma unidade específica no BNDES, Departamento de Biocombustíveis (DEBIO), para lidar com os projetos do setor; ii) incentivo à inovação e ao desenvolvimento tecnológico - criando-se o Programa Conjunto de Apoio à Inovação Tecnológica Industrial dos Setores Sucroenergético e Sucroquímico (PAISS), tendo como objetivo fomentar projetos de desenvolvimento, produção e comercialização de novas tecnologias industriais destinadas ao processamento da biomassa de cana-de-açúcar e projetos do etanol celulósico, também conhecido como etanol de segunda geração; iii) potencialização de externalidades positivas - como financiamentos a caldeiras de alta pressão para ampliar a produção e venda de energia elétrica; iv) estímulo à sustentabilidade socioambiental - com a criação, em meados de 2009, da Área de Meio Ambiente, financiando projetos sociais e ambientais; e v) contribuição para a formação de um mercado internacional de bioetanol. O BNDES coordenou a produção e participou da extensa agenda de divulgação do chamado "Livro Verde" do bioetanol, em parceria com o Ministério das Relações Exteriores e o Centro de Gestão e Estudos Estratégicos (Milanez; Cavalcanti; Favaret Filho, 2010).

Além destes programas, foi criado o Programa de Apoio do Setor Sucroalcooleiro (BNDES PASS), cuja finalidade foi financiar a estocagem de etanol para garantir o abastecimento do país na entressafra, e o Programa de Renovação dos Canaviais (Prorenova), destinado a financiar a renovação dos canaviais (Milanez; Nyko, 2012).

Embora o BNDES tenha destinado R \$ 4 bilhões para o programa Prorenova entre 2012 e 2014, a concessão de crédito foi menor em relação a este montante, de aproximadamente $35 \%$. Os fatores apontados para a menor concessão foram a taxa de juros, a burocracia, o endividamento do setor, as incertezas de mercado e a necessidade do cadastramento ambiental (Ferracioli; Bacha; Jacomini, 2016).

Borges e Costa (2012) analisaram o volume de desembolsos realizados pelo BNDES para o setor no período de 2001 até 2008. Propondo-se avaliar a relação entre os desembolsos, considerando as unidades da federação, a evolução e distribuição dos desembolsos por finalidade, e a relação entre a concentração e a produtividade das atividades do setor com os desembolsos, para as diferentes unidades federativas e grandes regiões. As finalidades de desembolsos mais relevantes foram as de implantação, expansão e financiamento para compra de máquinas e serviços. Esses três tipos de captações, bem como a modernização e a racionalização, impactam positivamente a ampliação, modernização e reorganização da produção. Constatando-se ainda concentração das captações, principalmente na região Centro-Sul, em específico no Sudeste e no 
estado de São Paulo. Intensificando a diferença de produtividade entre a região Centro-Sul e a Norte-Nordeste.

Silva (2017) salienta o fato de o Estado brasileiro em geral, e a concessão de créditos do BNDES em particular, em suas diferentes escalas de atuação, tender a agir em conformidade com os interesses dos grandes grupos econômicos, guiado pela lógica empresarial de crescimento da produção e sem considerar os custos sociais e as implicações territoriais desse processo. Além do mais, essas estratégias de financiamento (especialmente de grandes infraestruturas) realizadas com dinheiro público, tenderam a ser direcionadas e concentradas em um grupo seleto de produtores e empresas. Tudo isso se consolida em um contexto onde as corporações passaram a ter o controle das atividades exercidas no território, uma vez que o Estado deixou de lado sua função reguladora e passou a agir diretamente como viabilizador da produção capitalista.

\section{Fatores impulsionadores da maior destinação de crédito do BNDES para as grandes empresas}

Na década de 2000, apontam-se dois fatores como impulsionadores de uma maior destinação de crédito do BNDES para a grande empresa em relação à média e à pequena: (i) $o$ BNDES adotou a política das campeãs nacionais, fomentando $\mathrm{o}$ crescimento $\mathrm{e} a$ multinacionalização da grande empresa de capital brasileiro; (ii) o rating de crédito adotado pelo BNDES favorece o crédito para as grandes empresas em detrimento das pequenas e médias.

\section{Campeãs nacionais}

A atuação do Banco Nacional de Desenvolvimento Econômico e Social na década de 2000, principalmente entre 2007 e 2011, foi direcionada a acelerar o processo de conglomeração da economia por meio da política de incentivo às grandes empresas brasileiras, com o intuito de se tornarem competitivas e exercerem posição de liderança no cenário internacional. Está política foi batizada de Campeões Nacionais (Souza, 2012). Entendia-se como aspecto importante para a economia brasileira o BNDES auxiliar no crescimento e na multinacionalização das grandes empresas brasileiras. Acreditava-se que estas políticas protegeriam as empresas nacionais de serem compradas por multinacionais. Além disto, estas empresas trariam capital para o Brasil e gerariam empregos.

Conforme Souza (2012), as principais críticas à atuação do BNDES no período estão pautadas em duas vertentes, onde a primeira é ligada ao fato de o banco apoiar, principalmente com a política das campeãs nacionais, grupos e empresas fortes e consolidadas que não teriam dificuldade em acessar o crédito através do mercado financeiro, uma vez que o banco, por ser um fomentador do desenvolvimento público, não deveria se preocupar com projetos de maior retorno individual. A segunda crítica relaciona-se ao critério para se eleger empresas como JBS/Friboi, Mafrig, Fibria e Oi como empresas que se beneficiariam de uma grande quantidade de crédito, em muitos casos subsidiados, para o seu crescimento.

Lazzarini (2011) questiona a real necessidade da realização de tais aportes, uma vez que não há critérios sociais transparentes para tal, fortalecendo alegações de favorecimento de alguns grupos de determinados setores.

\section{Rating e risco de crédito adotado pelo BNDES}

Com o objetivo de gerenciar de maneira eficaz o risco de crédito ao qual são expostas, as instituições financeiras vêm buscando, durante os últimos anos, métodos mais eficazes e que possibilitem avaliações com maior precisão durante o processo de concessão de empréstimos, substituindo critérios que antes eram exclusivamente subjetivos (Brito; Assaf; Corrar, 2009). 
As políticas de crédito são fatores determinantes dentro do modelo de classificação, uma vez que o mercado e o público-alvo das concessões, bem como a fixação dos critérios e todos os fatores organizacionais (grau de independência técnica, perfil das pessoas envolvidas no processo decisório, entre outros) são elementos que constituem tanto a política de crédito quanto o próprio processo em si, sendo relevantes na definição do modelo adotado.

O BNDES utiliza um modelo desenvolvido ao longo de 1993 pelo Departamento de Crédito do BNDES para calcular o nível de risco das empresas e de grupos econômicos não financeiros (Lay et al., 2016). Bergamini Junior (1997) descreve o processo de desenvolvimento do modelo de classificação de risco do BNDES e suas características. Ressaltando-se que o BNDES, embora seja um banco de fomento público, possui características de avaliação de risco similares às utilizadas pelas instituições privadas, o modelo desenvolvido pelo BNDES possui três componentes de risco: a avaliação cadastral, matriz de fatores de risco quantitativos, matriz de fatores de riscos qualitativos. A disponibilidade de informações, que tenham um grau mínimo de confiabilidade e sejam transparentes, através de demonstrativos financeiros e contábeis, está diretamente vinculada ao risco de crédito. A maioria das empresas não fornecem tais informações para terceiros e, consequentemente, têm mais dificuldade em acessar o crédito.

A classificação de risco de empresas e grupos econômicos privados não-financeiros é realizada pelo BNDES através de sua área de crédito, previamente à análise dos projetos, efetuada em seguida pelas áreas operacionais. Após aprovada pelo comitê de crédito, a classificação de risco deve ser utilizada para balizar decisões relativas ao processo de crédito, tais como o acolhimento dos pleitos dos postulantes para análise técnica, a fixação da taxa de risco, a flexibilização das garantias, o estabelecimento de nível máximo de envolvimento do BNDES com seus mutuários e a concessão de limites de crédito para clientes de menor risco (Bergamini Junior, 1997).

Conforme Bergamini Junior (1997), quando as empresas que precisam ser analisadas são integrantes de um grupo, a avaliação de risco é centrada no desempenho consolidado do grupo, exigindo uma série de informações que precisam ser consolidadas e auditadas e que raramente são disponibilizadas pelos postulantes. Sendo assim, a exigência de tais demonstrativos auditados pode ser entendida como uma precondição para a elaboração de risco por parte das agências. A avaliação das informações auditadas para avaliar a concessão de crédito do banco inclui:

a) Análise do caráter, que objetiva a verificação e a comprovação da predisposição que o postulante tem para pagar o empréstimo através da obtenção de antecedentes cadastrais;

b) Análise das condições, da capacidade, do capital e do conglomerado, onde, através da aferição da capacidade de pagamento, é comprovado se o solicitante poderá pagar, em circunstâncias normais, o empréstimo; e

c) Análise do colateral, onde são mobilizadas as garantias reais e pessoas que sejam adequadas à operação de crédito em andamento, em termos de montante e liquidez para que, em eventual situação de não pagamento, tais garantias sirvam para honrar o compromisso.

d) Realizam-se avaliações quantitativas relacionadas ao nível de endividamento da empresa, a liquidez corrente, a rentabilidade do patrimônio líquido, alavancagem financeira e cobertura de financiamentos. As avaliações qualitativas consideram: a estratégia empresarial, qualificação da adequação da estratégia dos empreendedores visando atingir os níveis de competitividade em relação ao padrão vigente na indústria; a organização (definição da qualidade dos recursos humanos da empresa; grau de adequação da estrutura organizacional com relação aos objetivos da empresa; nível de profissionalização da administração; identificação e qualificação dos processos internos; análise da transparência e difusão dos relatórios); aspectos do mercado (Análise das condições vigentes do mercado que a empresa atua). 
e) São analisados ainda fatores como barreiras à entrada, possibilidades de diferenciação de produtos, de integração ou fusão, as possibilidades de melhor inserção da empresa na cadeia produtiva e a avaliação do posicionamento da empresa nos mercados dos quais participa e suas perspectivas.); Tecnologia (é realizado a qualificação do grau de adequação tecnológica da empresa, tanto em processos quanto em produtos e como a empresa se posiciona, nesse aspecto, estrategicamente ante o padrão vigente na indústria); e Gestão da Produção (Comparação dos aspectos globais da base técnico-produtiva em relação aos parâmetros vinculados à produção, produtividade, qualidade e flexibilidade além de outras variáveis relacionadas tanto à produção quanto às vendas).

\section{Materiais e métodos}

Utilizou-se o Anuário da Cana (2013) para coletar informações relativas ao ranking das $\operatorname{cem}^{1}$ (100) maiores empresas esmagadoras de cana-de-açúcar no Brasil e sobre a capacidade de moagem de cada empresa, além da capacidade de moagem total brasileira na safra 2012/2013.

Coletaram-se as informações relativas aos créditos diretos e indiretos concedidos de forma não automática entre 2002 e 2018 para as empresas do setor em Banco Nacional de Desenvolvimento Econômico e Social (2019). Para se auferir o montante de crédito disponibilizado pelo banco para cada empresa do setor foi realizada uma agregação dos valores disponibilizados pelo banco, pois as informações disponibilizadas referem-se às unidades industriais. Além disto, devido às Fusões \& Aquisições, ocorreram algumas alterações nos nomes das empresas no período analisado, necessitando-se pesquisar cada um dos "CNPJ's" e enquadrálos nos grupos.

A operação direta acontece quando o processo de concessão de crédito é realizado diretamente entre BNDES e o solicitante. Nesta modalidade, o risco da operação é integralmente do BNDES. Nesta modalidade, o valor deve ser maior que $\mathrm{R} \$ 10$ milhões e o solicitante necessariamente precisa apresentar o pedido por meio do Roteiro de Pedido e Financiamento. Em algumas linhas de financiamento que atendem setores específicos, é possível realizar o financiamento na modalidade direta sem a necessidade de atingir a cifra estipulada pelo Banco. A modalidade indireta é a mais recorrente entre os financiamentos realizados devido ao fato da instituição credenciada realizar o processo burocrático e de ela própria delinear questões referentes às garantias e exigências além dos prazos de pagamento. Nesse caso, a instituição assume o risco do projeto. Em relação ao risco, as instituições credenciadas são autorizadas a cobrar o spread do financiamento, tendo como limite um percentual que varia de acordo com a linha de financiamento, que em geral chega a 2,5\% a.a. sobre o valor do projeto, cabendo à instituição definir essa taxa respeitando o teto estipulado pelo BNDES (Barboza, 2018).

\section{Método de análise}

Com a perspectiva de realizar uma avaliação comparativa, optou-se por realizar uma comparação entre a captação de crédito do BNDES dos cem maiores grupos em moagem de canade-açúcar, com o intuito de se inferir se a obtenção de crédito seguiu a mesma tendência ou se teve uma intensidade maior ou menor se comparada à participação dos grupos econômicos na moagem de cana-de-açúcar. Esse método foi inspirado no trabalho de Souza, Ney e Ponciano (2015) pelo qual se analisou a distribuição dos financiamentos rurais entre os estabelecimentos agropecuários brasileiros, realizando uma comparação entre o valor da produção e a obtenção de financiamento rural para a atividade agrícola.

(1) Anuários da cana mais atualizados, como o de 2015, mencionam o ranking de moagem dos cinquenta maiores grupos. A utilização do Anuário da Cana (2013), por agregar cem grupos, possibilita uma abrangência para a realização da análise. Conforme NovaCana (2020), existem 256 grupos atuantes no setor sucroalcooleiro brasileiro. 
Inicialmente, foram mensurados os valores de crédito do BNDES concedidos para os cem maiores grupos. Posteriormente, foram comparados os montantes recebidos pelos grupos, de acordo com as informações disponibilizadas pelo BNDES, e o total de cana moída na safra de 2012/2013 por cada um destes grupos, de acordo com o Anuário da Cana (2013). Verificou-se o quanto cada grupo participa efetivamente da moagem total do Brasil no período em questão, assim como quanto cada grupo, proporcionalmente, recebeu de desembolso do banco.

Realizou-se ainda uma análise comparativa entre os índices de desigualdade e concentração da participação na moagem e na obtenção de crédito do BNDES, sendo o primeiro deles o índice razão de concentração (CR) onde, segundo Hoffmann (1998), "a razão de concentração das $k$ maiores empresas é, por definição, a proporção do valor total da produção da indústria", sendo assim, a razão de concentração das k maiores empresas é determinada pela equação 1 .

$$
R C_{K}=\sum_{i=1}^{K} y_{i}
$$

Onde

$$
y_{i}=\frac{X i}{n \mu}
$$

Sendo $X i$ a quantidade produzida pelo grupo, $n$ o número de grupos e $\mu$ a média de produção dos grupos.

O conceito de razão de concentração foi aplicado não somente no quesito de produção, mas também na questão do desembolso, permitindo a comparação dessas duas variáveis para os mesmos grupos de empresas.

Após a razão de concentração, mensurou-se a curva de Lorenz para a moagem dos grupos econômicos e para a obtenção de crédito do BNDES para os grupos econômicos.

Conforme Hoffmann (1998), o segmento de reta AB é denominado linha da perfeita igualdade, pois representa uma distribuição igualitária para as empresas; a área $\alpha$ é denominada área de concentração e, a relação entre a área de concentração $(\alpha)$ e a área do triângulo $\mathrm{ABC}$, é conhecida como índice de Gini (G), o qual é representado na equação 3.

$$
G=\frac{\alpha}{0,5}=2 \alpha
$$

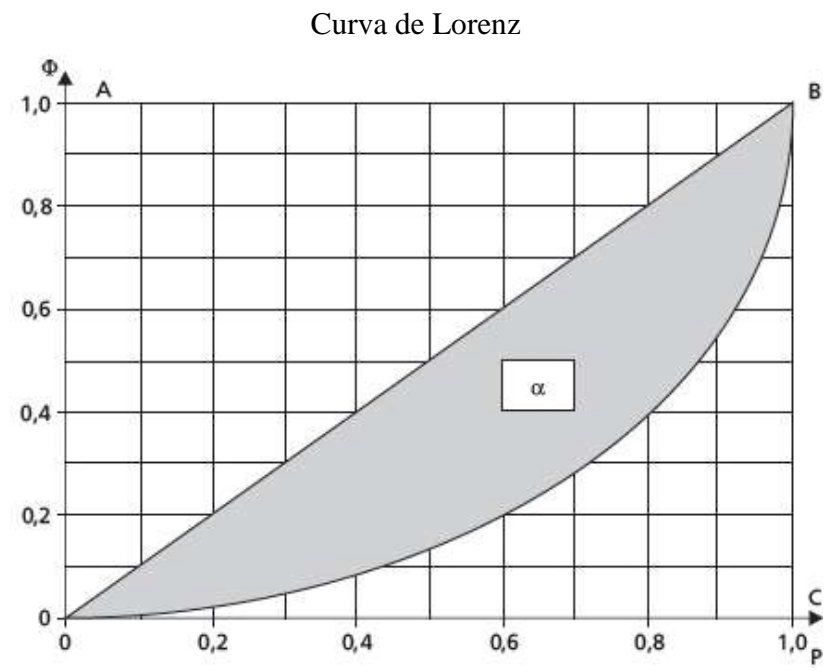

Fonte: Hoffmann (1998, figura 3). 


\section{Resultados e discussões}

Nos resultados e discussões apresentam-se inicialmente os valores absolutos da moagem e da concessão de crédito do BNDES para os cem grupos econômicos. Posteriormente serão apresentados os valores comparativos da razão de concentração, analisados os índices de desigualdade de Lorenz e mensurado o coeficiente de desigualdade de Gini.

Das operações do BNDES contratadas de forma direta e indireta não automática, destinadas à implantação da cogeração de energia elétrica, expansão de capacidade de moagem de cana-de-açúcar, implantação e modernização de unidade industrial, expansão e renovação do canavial, capital de giro, projeto de inovação tecnológica, apoio à construção de armazém para a estocagem de açúcar, financiamento de estocagem de etanol e ampliação da capacidade do terminal de transbordo, foram contratados aproximadamente 18,5 bilhões de reais entre $2002 \mathrm{e}$ 2018 para as cem maiores empresas por capacidade de moagem, conforme Figura 1.

Figura 1

Concessão de crédito do BNDES entre os anos de 2002 e 2018

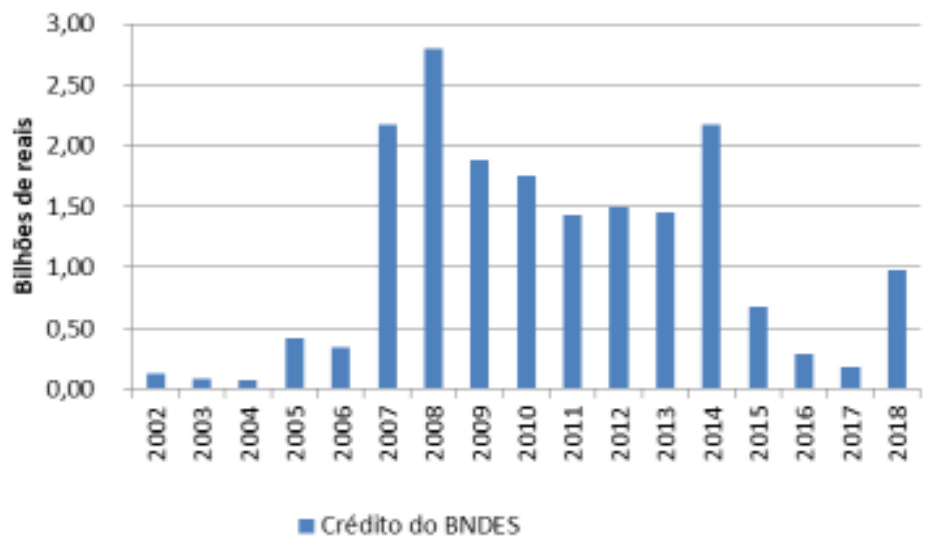

Fonte: Resultado da pesquisa.

Utilizando-se como base a moagem de cana-de-açúcar na safra 2012/2013 dos cem maiores grupos, considerando o total de aproximadamente 441 mil toneladas moídas pelos cem maiores grupos, o maior grupo moeu aproximadamente 53,4 milhões de toneladas e o centésimo moeu aproximadamente 1 milhão de toneladas, conforme Figura 2.

Figura 2

Moagem dos cem maiores grupos na safra 2013/2014

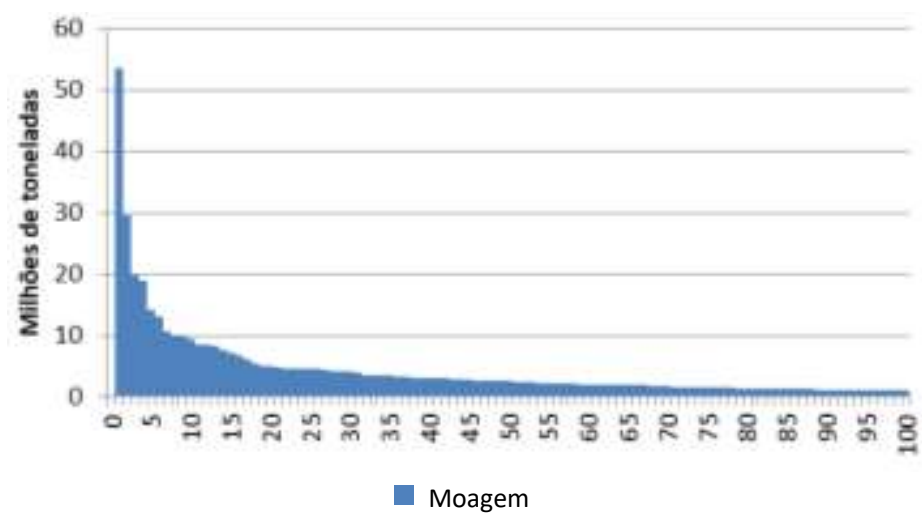

Fonte: Resultado da pesquisa. 
Considerando-se a concessão de crédito do BNDES para estes grupos no período de 2002 até 2018, foi concedido de crédito o montante de aproximadamente 18,6 bilhões de reais, conforme figura 3. O maior grupo captou aproximadamente $\mathrm{R} \$ 4,7$ bilhões de reais e o centésimo grupo não obteve crédito do BNDES. Percebe-se ainda que os dez maiores grupos captaram crédito do BNDES. Dos cinquenta maiores grupos, trinta e dois captaram crédito do BNDES. Do quinquagésimo primeiro ao centésimo grupo, cinco grupos captaram crédito do BNDES.

Figura 3

Concessão de crédito para cada uma das cem empresas com maior esmagamento na safra 2012/13

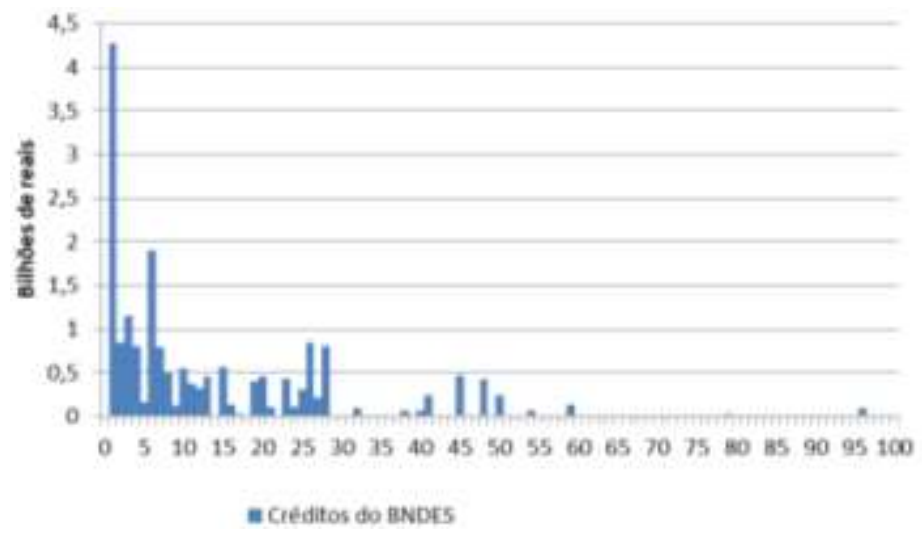

Fonte: Resultado da pesquisa.

A razão de concentração para o maior grupo, os cinco maiores grupos, os dez maiores grupos, os vinte maiores grupos e os cinquenta maiores grupos, mostrou-se maior para a concessão de crédito em relação à moagem, conforme tabela 2 . Ao considerar a moagem dos cem maiores grupos e a captação de crédito, o maior grupo obteve $23 \%$ da concessão de crédito do BNDES e $12 \%$ da moagem. Os cinquenta maiores grupos foram responsáveis por $82 \%$ da moagem e $98 \%$ da obtenção de crédito do BNDES.

Tabela 2

Razão de concentração por moagem e por captação de crédito da maior empresa, das cinco maiores empresas, das dez maiores empresas, das vinte maiores empresas e das cinquenta maiores empresas

\begin{tabular}{l|c|c}
\hline & Moagem & Captação de crédito \\
\hline $\mathrm{RC} 1$ & $12 \%$ & $23 \%$ \\
\hline $\mathrm{RC} 5$ & $31 \%$ & $39 \%$ \\
\hline $\mathrm{RC} 10$ & $43 \%$ & $60 \%$ \\
\hline $\mathrm{RC} 20$ & $58 \%$ & $74 \%$ \\
\hline RC50 & $82 \%$ & $98 \%$ \\
\hline
\end{tabular}

Fonte: Resultado da pesquisa.

A construção gráfica do Índice de Lorenz auxilia na visualização da distribuição dos créditos do BNDES por empresas e a participação das empresas na produção das cem maiores empresas por moagem na safra 2012/2103. A comparação da concentração entre os valores desembolsados pelo BNDES e a quantidade de moagem fica mais nítida comparando-se com a curva de Lorenz mensurada para o total de moagem de cana-de-açúcar na safra 2013/2014 (ver 
Figuras 4 e 5), pois a área de concentração da concessão de crédito, espaço compreendido entre a linha de perfeita igualdade e a curva, é maior do que a área de concentração da moagem.

Figura 4

Índice de Lorenz referente ao total de moagem das cem empresas com maior participação na moagem de cana-de-açúcar

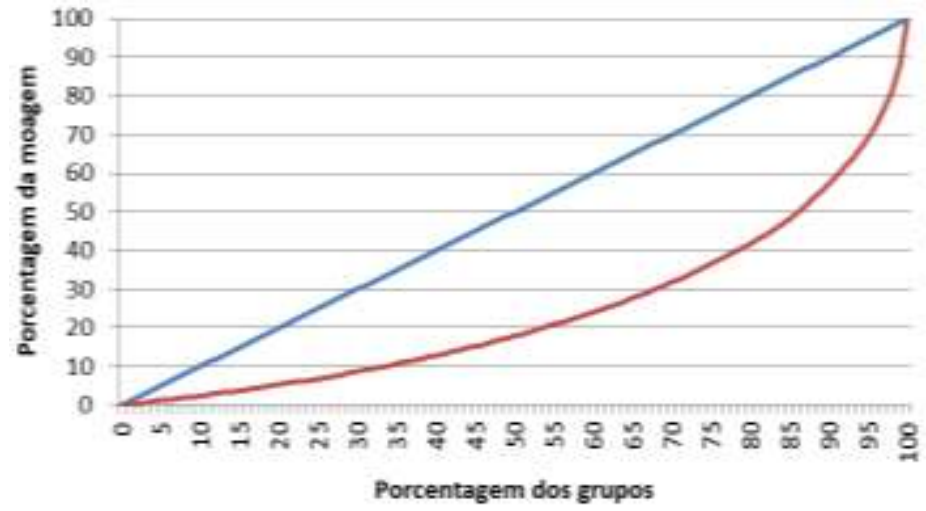

Fonte: Resultado da pesquisa.

Figura 5

Índice de Lorenz referente aos desembolsos realizados pelo BNDES das cem empresas com maior participação na moagem de cana-de-açúcar da safra 2012/2013

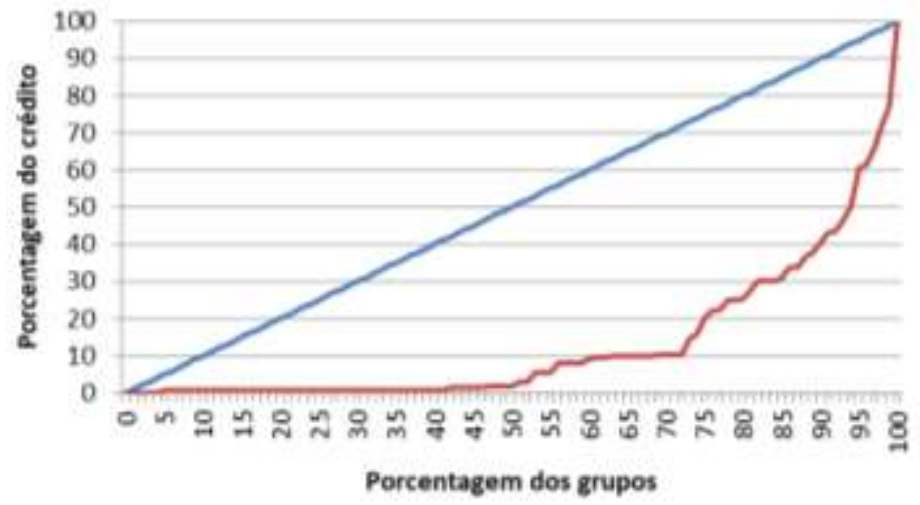

Fonte: Resultado da pesquisa.

Os quarenta últimos grupos classificados no ranking da moagem tiveram reduzido acesso ao crédito. A curva começa a se alterar a partir do quadragésimo primeiro, ampliando-se o acesso ao crédito. Os trinta maiores grupos acabaram ficando com a maior parte dos créditos do banco.

O coeficiente de Gini para a obtenção de crédito do BNDES mostrou-se maior em relação à moagem, conforme Tabela 3 , indicando maior desigualdade na obtenção de crédito do BNDES dentro dos cem maiores grupos em relação à desigualdade da moagem de cana-deaçúcar nestes grupos.

Tabela 3

Índice de Gini para a moagem e a concessão de crédito do BNDES

\begin{tabular}{c|c|c}
\hline & Moagem & Crédito \\
\hline Coeficiente de Gini & 0,513 & 0,74 \\
\hline
\end{tabular}

Fonte: Resultado da pesquisa. 


\section{Discussão}

Tanto os valores relativos à concessão de crédito do BNDES, como a razão de concentração, a curva de Lorenz e o coeficente de Gini, apontaram maior desigualdade e concentração na distribuição de crédito do BNDES em relação à capacidade de moagem para as cem maiores empresas do setor sucroalcooleiro entre 2002 e 2018.

A desigualdade na concessão de crédito do BNDES propicia vantagens competitivas para as maiores empresas do setor sucroalcooleiro em relação às menores. Conforme Ciani, Falkowski e Kancs (2012), a restrição de crédito é identificada como um fator crucial para determinar o desempenho e o desenvolvimento da empresa privada. Constata-se ainda o fato de a restrição de liquidez ser um fator limitante do uso de insumos pelas empresas, não apenas nos países em desenvolvimento, mas também nas economias desenvolvidas. A melhoria do acesso ao crédito pode levar ao aumento da produtividade e da produção tanto no curto como no longo prazo.

Os resultados reforçam as conclusões auferidas pelos trabalhos de Borges e Costa (2012) e Silva (2017), salientando o fato de a concessão de crédito do BNDES destinada ao fomento do setor na década de 2000 ter tido uma natureza de mercado, podendo ser denominada "modernização conservadora", destinando um maior volume de crédito para os maiores grupos econômicos no setor em relação aos menores.

Devido à internacionalização do setor na década de 2000 relatada por Pinto (2011) e Silva (2017), ocorrendo a entrada de grandes empresas multinacionais na produção sucroalcooleira como a Shell (através da Raízen, joint venture da Cosan, grupo nacional, e da Shell), a British Petroleum (inicialmente através da aquisição da Tropical Bioenergia e hoje atuante como BP biocombustíveis) e a Louis Dreyfus. Não se pode afirmar ter ocorrido uma política de campeãs nacionais, mas sim concessão de crédito com o intuito de suprir uma oportunidade com as exportações de açúcar, o mercado interno de etanol anidro e hidratado e a expectativa de exportaçõesde etanol.

O destino de crédito do BNDES pode ser apontado como um dos fatores para se intensificar a concentração econômica na participação das grandes empresas na moagem de canade-açúcar, constatadas nos trabalhos de Baccarin, Gebara e Factore (2009) e Figueira, Belik e Vicente (2014b), pois o acesso ao crédito possibilita compra de máquinas e equipamentos, plantio de cana-de-açúcar e renovação do canavial.

A expansão do crédito do BNDES para o setor sucroalcooleiro no período de 2002 até 2018 pode ter contribuído também para ampliar a concentração dos grandes estabelecimentos na produção agropecuária. Baccarin, Oliveira e Mardegan (2020) ressaltam o crescimento da participação dos estabelecimentos agropecuários paulistas de mais de 1.000 hectares na área agrícola do estado, passando de 27,4\% em 1995/96 para 36,4\% em 2006. O crescimento da produção canavieira no estado contribuiu para este fenômeno, pois ocorreu elevação da participação dos estabelecimentos com mais de 1.000 hectares na área ocupada para a produção de cana-de-açúcar, passando de 47,7\% em 1996 para 64,4\% em 2006. Esta ampliação se deve ao crescente uso da terra sob arrendamento ou parceria, para se produzir a cana própria das usinas. A integração vertical entre usina e lavoura canavieira para a produção da cana-de-açúcar utilizada no processo produtivo é uma característica histórica da gestão da produção do setor sucroalcooleiro brasileiro. Destaca-se ainda a mecanização do corte de cana-de-açúcar no período, dificultando a permanência de pequenos e médios fornecedores. 
Por fim, as concessões de crédito do BNDES auxiliaram a reforçar as desigualdades territoriais da produção. Borges e Costa (2012), ao analisar a distribuição dos desembolsos do BNDES no setor sucroenergético no Brasil no período de 2001 até 2008, constataram predominância da região Centro-Sul, com 96,58\%, enquanto a região Norte-Nordeste participou com apenas 3,42\%. Silva (2017) salienta o fato de a concessão de créditos do BNDES tender a agir em conformidade com a lógica empresarial de crescimento da produção e sem considerar as implicações territoriais desse processo.

\section{Conclusões}

Na década de 2000, ocorreu crescimento da produção de cana-de-açúcar e, consequentemente, de açúcar e etanol. O crescimento da produção do setor foi acompanhado de um aumento do tamanho das usinas e maior concentração setorial. Maiores grupos econômicos, com mais de uma usina, ampliaram a participação sobre a produção do setor.

O BNDES teve papel de destaque na concessão de crédito para as empresas privadas atuantes no setor sucroalcooleiro no período, permitindo assim a realização de investimentos através da renovação e plantação de novos canaviais, investimentos em ampliação da capacidade produtiva, compra e modernização de máquinas e equipamentos.

O objetivo do trabalho foi averiguar se ocorreu concentração na concessão de créditos do BNDES para os grupos econômicos atuantes no setor sucroalcooleiro na década de 2000. Para isso, mensurou-se comparativamente a concessão de créditos do BNDES para os cem maiores grupos do setor sucroalcooleiro entre 2002 e 2018. Mensurou-se ainda, comparativamente, a concessão de crédito do BNDES e a quantidade de moagem de cana-de-açúcar, a razão de concentração, e construiu-se as curvas de Lorenz e mensurou-se os coeficientes de Gini.

Em todos os indicadores mensurados constatou-se maior concentração e desigualdade na concessão de crédito, inclusive em relação à participação na moagem de cana-de-açúcar. Alguns números da razão de concentração ilustram estas características: o maior grupo teve acesso a $23 \%$ do crédito e participou em $12 \%$ da moagem de cana-de-açúcar. Os cinco maiores, obtiveram $39 \%$ de acesso ao crédito e $31 \%$ da moagem. Os dez maiores obtiveram $60 \%$ de crédito e participaram com $43 \%$ da moagem.

Além do volume de concessão de crédito, notou-se ainda dificuldades com relação ao acesso ao crédito. Todos os dez maiores grupos captaram crédito do BNDES. Dos cinquenta maiores grupos, trinta e dois captaram crédito do BNDES. Do quinquagésimo primeiro ao centésimo grupo, sete grupos captaram crédito.

O presente trabalho constatou maiores repasses de crédito do BNDES para as maiores empresas do setor sucroalcooleiro, devendo-se realizar novos trabalhos com o intuito de averiguar os motivos pelos quais as grandes empresas possuem maior acesso ao crédito do BNDES em relação às menores empresas.

\section{Referências bibliográficas}

ANUÁRIO DA CANA. Ranking de moagem. Grupos. Ribeirão Preto, SP: Ed. Pró Cana Brasil, 2013. 
BACCARIN, J. G. A constituição da nova regulamentação sucroalcooleira. Brasília: Universidade de Brasília, Centro de Estudos Avançados Multidisciplinares, Núcleo de Estudos Agrários; São Paulo: Editora Unesp, v. 5 n. 22, 2005. 237p.

BACCARIN, J. G. Sistema de produção agropecuário brasileiro: característica e evolução recente. São Paulo. Cultura Acadêmica Editora. Unesp. Pró-reitoria de Graduação/Unesp. 254p. 2011.

BACCARIN, J. G.; GEBARA, J. J.; FACTORE, C. O. Concentração e integração vertical do setor sucroalcooleiro no centro-sul do Brasil, entre 2000 e 2007. Informações Econômicas, v. 39, n. 3, mar. 2009.

BACCARIN, J. G.; OLIVEIRA, J. A; MARDEGAN, G. E. Monocultura e concentração da terra: efeitos da expansão da cana-de-açúcar na estrutura fundiária do Estado de São Paulo, Brasil. Revista Núcleo de Estudos, Pesquisas e Projetos de Reforma Agrária - NERA (Unesp), v. 23, p. 38-62, 2020.

BANCO NACIONAL DE DESENVOLVIMENTO ECONÔMICO E SOCIAL. Operações contratadas na forma direta $e$ indireta não automática. Disponível em: https://www.bndes.gov.br/wps/portal/site/home/transparencia/centraldedownloads/. Acesso em: 7 out. 2019.

BARBOZA, C. C. Desembolsos do BNDES para o setor sucroalcooleiro: estudo multicaso envolvendo duas instituições financeiras e um grupo econômico. 2018. 60p. Trabalho de Conclusão de Curso (Bacharelado - Administração)-Universidade Estadual Paulista (Unesp), Faculdade de Ciências Agrárias e Veterinárias, Jaboticabal, SP, 2018.

BELIK, W.; PEROSA, B. B.; FIGUEIRA, S. R. F.; VICENTE, A. K. Milling capacity and supply competition in sugar-ethanol industry in São Paulo, Brasil. Geografia, Rio Claro. Impresso, v. 42, p. 39-56, 2017.

BELIK, W.O financiamento da agropecuária brasileira. In: CONGRESSO DA SOCIEDADE BRASILEIRA DE ECONOMIA, ADMINISTRAÇÃO E SOCIOLOGIA RURAL, 51, Belém, 2013. Anais... 21p.

BERGAMINI JUNIOR, S. Classificação de risco: o modelo em uso no BNDES. Revista do $B N D E S$, Rio de Janeiro, v. 4, n. 5, p. 71-100, dez. 1997.

BORGES, A. C. G.; COSTA, V. M. H. M. Distribuição dos desembolsos do BNDES no setor sucroenergético no Brasil. Estudos Geográficos, v. 9, n. 2, p. 73-88, 2012. Disponível em: http://hdl.handle.net/11449/133622.

BRITO, G. A. S.; ASSAF NETO, A.; CORRAR, L. J. Sistema de classificação de risco de crédito: uma aplicação a companhias abertas no Brasil. Revista Contabilidade \& Finanças, USP, São Paulo, v. 20, n. 51, p. 28-43, set./dez. 2009.

BRITO, G. A. S.; ASSAF NETO, A. Modelo de classificação de risco de crédito de empresas. Revista Contabilidade \& Finanças, USP, São Paulo, v. 19, n.46, p 18-29, jan./abr. 2008.

BROWN, K.; MOLES, P. Credit risk management. Edinburgh, United Kingdom: Edinburgh Business School, 2014. 58p. 
CASTRO, N. C.; DANTAS, G. A.; BRANDÃO, R. A dinâmica estrutural do setor sucroenergético como elemento indutor de investimentos em bioeletricidade. In: CONGRESSO SOBRE GERAÇÃO DISTRIBUÍDA E ENERGIA (AGRENER), Campinas, SP, 2010.

CIAIAN, P.; FALKOWSKI, J.; KANCS, D. Access to credit, factor allocation and farm productivity: evidence from the CEE transition economies. Agricultural Finance Review, v. 72, n. 1, p. 22-47, 2012.

CIAIAN, P.; SWINNEN, J. F. M. Credit market imperfections and the distribution of policy rents. American Journal of Agricultural Economics, Nov. 2009.

FERGUSON. C. E. Microeconomia. 20. ed. Rio de Janeiro: Forense Universitária, 2003. 610p.

FERRACIOLI, K. G.; BACHA, C. J. C.; JACOMINI, R. L. Linhas de crédito do BNDES para o setor sucroenergético brasileiro. Revista de Política Agrícola, Ano XXV, n. 3, jul./ago./set. 2016.

FERREIRA, E. R.; ALVES, F. D. Organização espacial da cana-de-açúcar no estado de São Paulo: uma análise evolutiva. In: Ferreira, Darlene Aparecida de Oliveira; Ferreira, Enéas Rente. (Org.). Estudos agrários: conceitos e práticas. Rio Claro: Ed. da Pós-Graduação em Geografia/IGCE/Unesp, v. 1, p. 000-231, 2009.

FIGUEIRA, S. R. F.; BELIK, W.; VICENTE, A. K. Escala e competição na agroindústria canavieira no Estado de São Paulo. In: CONGRESSO DE ECONOMIA E SOCIOLOGIA RURAL, 52, Goiânia, GO, 2014a. Anais...

FIGUEIRA, S. R. F.; BELIK, W.; VICENTE, A. K. Escala e concentração das usinas de açúcar e álcool e empresas do setor no Estado de São Paulo. In: CONGRESSO DE ECONOMIA E SOCIOLOGIA, 52, Goiânia. GO, 2014b. Anais...

FIGUEIRA, S. R. F.; PEROSA, B. B.; BELIK, W. Expansão do setor sucroalcooleiro no estado de São Paulo: evidencias sobre a escala de moagem das usinas na década de 2000. In: CONGRESSO DE ECONOMIA E SOCIOLOGIA RURAL, 51, Belém, PA. 2013. Anais...

HOFFMANN, R. Estatística para economistas. São Paulo: Pioneira, 1998. 430p.

INSTITUTO BRASILEIRO DE GEOGRAFIA E ESTATÍSITICA. Produção Agrícola Municipal. Sistema IBGE de Recuperação Automática (SIDRA). Disponível em: https://sidra.ibge.gov.br/tabela/1612. Acesso em: 27 mar. 2020.

LAWAL, R. Y.; MANGS, N. J.; YUNUS, A. B.; ABDULRAFIU, D. Effect of Bank's credit on the performance of small and medium scale enterprise in Nigeria. Ilorin Journal of Human Resource Management (IJHRM), v. 3, n. 2, p. 101-110, 2019.

LAY, et al. Relação do modelo utilizado pelo BNDES para classificação de riscos com as classificações de standard \& poor's, Moody's e Fitch. In: SBPO SIMPÓSIO BRASILEIRO DE PESQUISA OPERACIONAL, 48, Vitória, ES, 27 a 30 set. 2016. Anais... p. 1224-1235.

LAZZARINI, S. G. Capitalismo de laços. Os donos do Brasil e suas conexões. Rio de Janeiro: Elsevier, 2011. p. 184.

LOOTTY, M.; SZAPIRO, M. Economia de escala e escopo. In: KUPFER, D.; HASENCLEVER, L. Economia industrial. Fundamentos teóricos e práticos no Brasil. Rio de Janeiro: Campus, 2002. p. 43-70. 
MILANEZ, A. Y.; CAVALCANTI, C. E. S.; FAVARET FILHO, P. S. C. F. O papel do BNDES no desenvolvimento do setor sucroenergético. In: ALÉM, A. C.; GIAMBIAGI, F. O BNDES em um Brasil em transição. 465p. Rio de Janeiro: Banco Nacional de Desenvolvimento Econômico e Social - BNDES, 2010. p. 335-347.

MILANEZ, A.; NYKO, D. O futuro do setor energético e o papel do BNDES. In: BNDES 60 anos: perspectivas setoriais. Rio de Janeiro: Banco Nacional de Desenvolvimento Econômico e Social, 2012. p. 62-87. Disponível em: http://web.bndes.gov.br/bib/jspui/handle/1408/7062. Acesso em: 7 out. 2020.

NOVACANA. Grupos econômicos atuantes no setor sucroalcooleiro. Disponível em: https://www.novacana.com/usinas_brasil. Acesso em: 25 mar. 2020.

PINDYCK, R. S.; RUBINFELD, D. L. Microeconomia. 6. ed. São Paulo. Ed. Prentice Hall, 2005. p. 641.

PINTO, M. J. A. Investimentos diretos estrangeiros no setor sucroenergético. 2011. Dissertação (Mestrado em Administração)-Programa de Pós-Graduação em Administração da Faculdade de Economia, Administração e Contabilidade da Universidade de São Paulo, Ribeirão Preto. 2011. $174 \mathrm{p}$.

POSSAS, M. L. Estruturas de mercado em oligopólio. São Paulo: Editora Hucitec, 1990. 191p.

SANTOS. R. B. N. dos; BRAGA, M. J. Impactos do crédito rural na produtividade da terra e do trabalho nas regiões brasileiras. Economia Aplicada, Ribeirão Preto, v. 17, n. 3, p. 299-324, 2013.

SHIFERAW, K.; GEBREMEDHIN, B.; ZEWDIE, D. L. Factors affecting household decision to allocate credit for livestock production. Evidence from Ethiopia. Agricultural Finance. Review, v. 77, n. 4, p. 463-483, 2017. https://doi.org/10.1108/AFR-06-2016-0062.

SILVA, L. R. O BNDES e a sustentação do setor sucroenergético no Brasil: implicações territoriais no contexto neoliberal e de financeirização. 2017. Dissertação (Mestrado em Geografia. Área de Concentração: Geografia e Gestão do Território)-Programa de PósGraduação em Geografia da Universidade Federal de Uberlândia (PPGEO/UFU), Uberlândia, 2017.

SOUZA, A. M. BNDES, campeões nacionais, expansionismo e integração regional. In: CONGRESO LATINOAMERICANO DE HISTORIA ECONÓMICA, 3; JORNADAS DE HISTORIA ECONÓMICA SIMPOSIO 2: INVERSIÓN DIRECTA EXTRANJERA Y EMPRESAS MULTINACIONALES EN AMÉRICA LATINA (1900-2010), 23, San Carlos de Bariloche, 23 al 27 Oct. 2012. p. 1-20.

SOUZA, P. M.; NEY, M. G.; PONCIANO, N. J. Análise da distribuição dos financiamentos rurais entre os estabelecimentos agropecuários brasileiros. Revista de Economia e Sociologia Rural, Piracicaba, SP, v. 53, n. 2, p. 251-270, abr./jun. 2015.

STIGLITZ, J. E.; WEISS, A. Credit rationing in markets with imperfect information. The American Economic Review, v. 71, p. 393-410, jun. 1981.

UBESIE, M. C.; ONUAGULUCHI, IF; MBAH, A. M. Effect of deposit money banks credit on small and medium scale enterprises growth in Nigeria. International Journal of Finance and Accounting, v. 6, n. 5, p. 117-132, 2017. 